\title{
Perceived accessibility is an important factor in transport choice - Results from the AVENUE project
}

\author{
C.E. Scheepers ${ }^{a, b, *}$, G.C.W. Wendel-Vos ${ }^{b}$, E.E.M.M. van Kempen ${ }^{c}$, E.L. de Hollander ${ }^{b}$, \\ H.J. van Wijnen ${ }^{c}$, J. Maas ${ }^{\mathrm{d}}$, F.R.J. den Hertog ${ }^{\mathrm{e}}$, B.A.M. Staatsen ${ }^{\mathrm{c}}$, H.L. Stipdonk ${ }^{\mathrm{f}}$, \\ L.L.R. Int Panis ${ }^{\text {g,h }}$, P.J.V. van Wesemael ${ }^{\mathrm{i}}$, A.J. Schuit ${ }^{\mathrm{a}, \mathrm{b}}$ \\ ${ }^{a}$ VU University Amsterdam, Department of Health Sciences and EMGO institute for Health and Care Research, De Boelelaan 1105, 1081 HV Amsterdam, \\ The Netherlands \\ ${ }^{\mathrm{b}}$ National Institute for Public Health and the Environment, Centre for Nutrition, Prevention and Health Services, PO Box 1, 3720 BA Bilthoven, \\ The Netherlands \\ ${ }^{\mathrm{c}}$ National Institute for Public Health and the Environment, Centre for Sustainability, Environment and Health, PO Box 1, 3720 BA Bilthoven, \\ The Netherlands \\ ${ }^{\mathrm{d}}$ VU University Medical Centre, EMGO Institute, 1007 MB Amsterdam, The Netherlands \\ e National Institute for Public Health and the Environment, Centre of Health and Society, 3720 BA Bilthoven, The Netherlands \\ ${ }^{\mathrm{f}}$ SWOV Institute for Road Safety Research, 2509 AC Den Haag, The Netherlands \\ ${ }^{\mathrm{g}}$ Flemish Institute for Technological Research (VITO), Health Unit, $2400 \mathrm{Mol}$, Belgium \\ ${ }^{\text {h }}$ School for Mobility, Hasselt University, 3590 Diepenbeek, Belgium \\ ${ }^{\mathrm{i}}$ Technical University Eindhoven, Department of the Built Environment, 5600 MB Eindhoven, The Netherlands
}

\section{A R T I C L E I N F O}

\section{Article history:}

Received 4 September 2015

Received in revised form

19 December 2015

Accepted 8 January 2016

Available online 11 February 2016

Keywords:

Neighbourhood

Car

Cycling

Walking

Active transport

Environment

\begin{abstract}
A B S T R A C T
Background: Stimulating active transport by encouraging replacement of short-distance car trips by active transport modes such as cycling or walking has become a popular policy strategy. It has been suggested that neighbourhoods, designed to facilitate healthy behaviour, can influence a person's behavioural choices such as transport choice. In the present study, we investigated the association between perceived accessibility of facilities and transport choice for three different trip purposes (shopping, going to public natural spaces, and going to sports facilities) in the Netherlands.

Methods: An online questionnaire $(N=3663)$ was used to collect data concerning transport choice for the general Dutch population over a period of one calendar year starting July 2012. Logistic regression analyses were used to model the odds of cycling versus car use and to model the odds of walking versus car use. Results: When perceived accessibility by car is high, persons were less likely to use active transport modes (OR range: 0.09-0.66) and when perceived accessibility by active transport modes is high, persons were more likely to use the bicycle (OR range: $2.18-10.43$ ) or walk (OR range: $2.97-11.22$ ).

Conclusions: Our results showed a strong association between perceived accessibility and transport choice even after adjusting for personal and environmental characteristics. Our results suggest that perceived accessibility should be taken into account when stimulating a shift from car use to cycling or walking.
\end{abstract}

(c) 2016 Elsevier Ltd. All rights reserved.

\section{Introduction}

Stimulating active transport by encouraging replacement of short-distance car trips by active transport modes such as cycling or walking has become a popular policy strategy (De Nazelle et al., 2011). Stimulating a mode shift from car to active transport modes has several beneficial health effects, e.g. an increase of the level of physical activity (Engbers and Hendriksen, 2010; Saelens et al., 2003; De Nazelle et al., 2011) as well as a reduction in air pollution (De Hartog et al., 2010), greenhouse gas emissions (Lindsay et al., 2011) and noise levels (Van Kempen et al., 2010). The effects on road safety depend however on age and gender (Stipdonk and Reurings, 2012). To give measures aiming

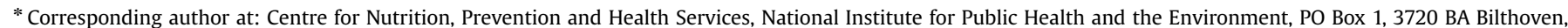
The Netherlands. Tel.: +3130274 3312; fax: + 31302744407.

E-mail address: eline.scheepers@minienm.nl (C.E. Scheepers).
} 
to induce a mode shift from car to active transports modes a reasonable chance of success, car trips that may potentially be replaced by bicycle trips should not exceed a feasible cycling distance. A distance of up to $7.5 \mathrm{~km}$ then comes to mind (Scheepers et al., 2014).

Behaviour is assumed to be affected by several personal and contextual factors. Personal (for example age, gender and educational level) and behavioural factors (attitudes, social norms and self-efficacy) define the intentions to behave. The moment when the intention to perform certain behaviour is turned into actual behaviour is influenced by barriers and skills (De Vries et al., 2003). An important set of barriers lies within the environment, or more specifically, in the interaction between individuals and their direct living environment (for example the type of neighbourhood someone is living in) (Van Kempen et al., 2010).

It has been suggested that neighbourhoods designed to facilitate healthy behaviour can influence people's behavioural choices (e.g. transport choice) (Timmermans, 2013). In previous analyses, we found an association between neighbourhood typology and transport choice (Scheepers et al., 2013). However, in these previous studies we were unable to draw conclusions on the impact of more specific environmental characteristics on transport mode choice. For example, proximity and connectivity are two aspects of land use known to influence transport choice and to be related to the accessibility of destinations (Cerin et al., 2007). Accessibility can be defined as how easily an individual can pursue an activity of a desired type, at a desired location, by a desired mode, and at a desired time (Bhat et al., 2000). Accessibility has long been recognised as an important characteristic of urban areas in particular, reflecting the ability of the population to participate in out-of-home activities (Metz, 2013). Observational and experimental studies specifically addressing accessibility as a determinant of transport choice rather than for example cycling for transport are scarce. Accessibility of destinations can be estimated by asking how people perceive the accessibility of certain destinations by means of questionnaires or interviews (perceived accessibility), by calculating a walkability index, or by using information from national or local databases and maps such as physical characteristics of destinations (e.g. the squared km public natural spaces), usually processed by means of geographical information systems (GIS; objective accessibility). A large proportion of the studies investigating the association between accessibility and transport choice that included objective accessibility used existing, readily available data sources. However, these sources generally come with shortcomings with regard to specific research questions. For example, natural outdoor environments will include a mix of elements that may be assumed to be associated with transport modes to a more or lesser extent. Also, these sources may not distinguish small grocery stores from larger supermarkets or shopping malls.

Previous studies have shown a low level of agreement between perceived and objective accessibility measures (McCormack et al., 2008; Ball et al., 2008). This low correlation can be explained by the fact that people process and store information about their environment according to their own attitudes, motivations, and preferences (Dewulf et al., 2012). For example, when people are not aware of the presence of facilities in their direct living environment, they are more likely to travel longer distances and thus less likely to use active transport modes. The physical presence of facilities will not necessarily mean that people will use them. Because of this discrepancy between objective and perceived accessibility, it is important to take both into account when studying the association between accessibility and transport choice.

The aim of the present study was to provide insight into the association between perceived accessibility and choice of transport mode (car, cycling and walking) for shopping trips, trips to sports facilities and trips to public natural spaces while taking into account objective accessibility. For this purpose, a questionnaire was designed in which we directly asked about transport choice and perceived accessibility with regard to three specific trip purposes: shopping facilities, sports facilities and public natural spaces. Data from this questionnaire was enriched with objective accessibility measures. This specifically enabled us to investigate the association between perceived accessibility and transport choice for these three different trip purposes as a primary objective, while taking into account objective accessibility. In this study we focus specifically on the situation in the Netherlands. The Netherlands are characterized by a high share of active transport, a unique cycling environment and a large amount of short trips (Ministry of Transport Public Works and Water Management, 2009; Pucher and Buehler, 2008). Results of this study will be valuable since the influence of perceived accessibility will be investigated in an environment that is already characterized by a good objective accessibility of facilities.

\section{Methods}

This study is part of the impActs of actiVE traNsport in Urban Environments (AVENUE) project (Textbox 1). Aim of the AVENUE project is to provide in-depth information on characteristics of short car and active (cycling and walking) transport trips and on the feasibility of replacing short car trips with active transport modes. The data presented in this paper came from the online questionnaire which was specially designed to investigate transport choice for the predefined trip purposes (see for more information Textbox 1). Data collection was conducted over a period of one calendar year starting July 2012, in which on each consecutive day an average of 10 participants filled in the questionnaire. The questionnaire was completed by total of 3663 persons (Fig. 1). Since ethical clearance is only needed when daily life of participants is influenced or participants should perform specific actions an ethical clearance approval was not warranted and therefore not obtained. The data were anonymized prior to the moment that the authors received the dataset from the owner of the internet panel. The authors did not have access to any identifying information.

Our study population was shown to be quite representative for the general Dutch population with respect to mobility behaviour and personal characteristics (Appendix A). Comparison of respondents and non-respondents showed significant differences for age, household structure and making trips to public natural spaces (Appendix B). Compared to the respondents, among the non-respondents, a slightly lower proportion (89.4\% vs. 90.5\%) met the selection criteria for the main questionnaire.

\subsection{Questionnaire data}

In our statistical analyses we took several variables into account that originated from the online questionnaire: transport mode, perceived accessibility, personal characteristics and perceived characteristics of the direct living environment. 
Textbox 1-The AVENUE project.

impActs of actiVE traNsport in Urban Environments (AVENUE) project

The AVENUE project is commissioned by the Dutch National Institute for Public Health and the Environment as part of the strategic research program. The project started in 2011 and will last till march 2015.

\section{Aim}

AVENUE aims to provide in-depth information on characteristics of short car and active (cycling and walking) transport trips and on the feasibility of replacing short car trips with active transport modes.

\section{Context}

AVENUE has a focus on Dutch national representative data. AVENUE includes four trip purposes:

\section{- Shopping}

- Going to public natural spaces

- Going to sports facilities

- Commuting

We chose these particular purposes since it was expected that these purposes are of interest to policy makers and developers of intervention measures since they imply a clear set of stakeholders and partners involved in case an intervention or policy measure in this domain is considered.

\section{Approach}

AVENUE uses a multidisciplinary approach and includes a combination of qualitative (focus groups, policy analysis) and quantitative methods (systematic literature review, questionnaire and (secondary) data analysis).

\section{Qualitative data collection}

As part of the AVENUE project focus groups were conducted to gather insight in the motivations for transport choice for the four trip purposes. A policy analysis was conducted to understand the character and shape of transport policies aiming to induce a mode shift as well as identifying Health in All Policies approaches aiming to induce such a mode shift.

\section{Quantitative data collection}

A systematic review was conducted to systematically review the effectiveness of interventions aiming to induce a mode shift as well as to obtain insight in the tools that have been used in these interventions. Secondary data analysis has been performed on data of Mobility Research Netherlands to determine the association between personal and neighbourhood characteristics with shortdistance trips and to define target groups for future interventions.

An online questionnaire was designed to investigate transport choice (car, cycling, walking) for the four trip purposes included in the study. For this questionnaire, AVENUE made use of an existing (internet) panel $(N \approx 35000)$ representative for the general Dutch population based on age, gender and education level. A random sample of 8813 persons of 18 years (the minimum age to get a driver's license in The Netherlands) or older was drawn. A total of 4444 individuals $(50.4 \%$ of the sample) started the questionnaire. Data collection was conducted over a period of one calendar year starting July 2012, in which on each consecutive day an average of 10 participants filled in the questionnaire.

Preceding the actual questionnaire, two selection questions were asked:

1) To what extent does your health hamper you in (a) walking; (b) cycling; (c) driving a car?

Possible answers: very much, somewhat, practically not, not at all.

2) How many times a week do you normally travel distances up to $7.5 \mathrm{~km}$ by (a) car; (b) bicycle; (c) foot?

Possible answers: never, < once a week, $\geq$ once a week, do not know

Only those that indicated that they were not hampered ('practically not' or 'not at all') to use at least one of the three transport modes and had made at least one short trip a week using at least one of the transport modes ( $N=4021 ; 45.6 \%$ of the sample; $90.5 \%$ of the respondents) were offered the main questionnaire, which included questions about:

1. Personal characteristics (date of birth, gender, household composition). Information about postal code, marital status, educational level and work situation was readily available from the panel background dataset;

2. Characteristics of the home and living environment and satisfaction with the home and living environment;

3. Trip purposes and accompanying transport mode

a. Do you ever travel a distance up to $7.5 \mathrm{~km}$ directly from home (a) to go shopping, (b) to go to public natural spaces, (c) to go to sports facilities, and/or (d) for commuting purposes?

b. If yes, for which combination of trip purpose and transport mode?

4. For every combination of trip purpose (max 4) and transport mode (max 3): Factors influencing transport mode choice (e.g. weather, safety, noise, smell, living environment, factors related to the route taken and combining this trip with other trip purposes (combined trip purposes)).

5. Perceived general health and mental health, height and weight

6. Lifestyle (smoking, alcohol consumption, physical activity and sedentary behaviour).

3308 participants of the 4361 who did not start the questionnaire, received another link to a short non-response questionnaire. A total of 382 respondents completed the non-response questionnaire.

Since we had information about the postal codes of the areas of the participants' addresses (four-digit and six-digit postal codes), we were able to merge our dataset with several (objective) environmental characteristics. 


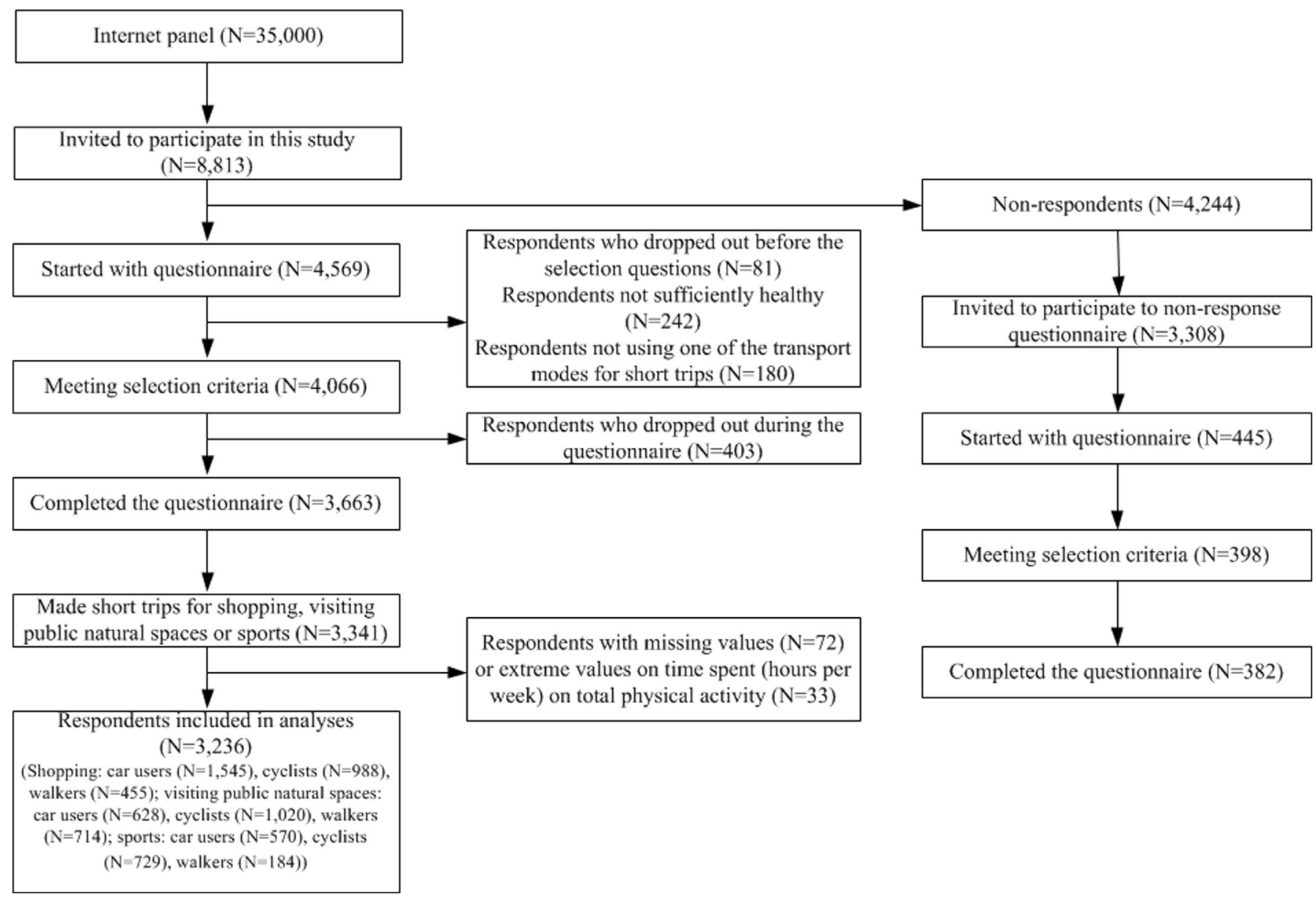

Fig. 1. Flow-chart showing selection of study population.

\subsection{Transport mode}

A distinction was made between trip purposes since we found in an earlier study that trip purpose is associated with transport choice and we expected that for the three trip purposes different aspects will influence transport choice (Scheepers et al., 2013). For each of the separate trip purposes under investigation, respondents were classified into one of three transport groups based on their preferred transport choice: car users, cyclists, and pedestrians. Their preferred choice for each particular trip purpose was inferred from their frequency of using the car, cycling, or walking. When people reported both the car and active modes with equal frequency they were categorized as car users, as the primary aim was to provide in-depth information on the feasibility of replacing short car trips with active transport modes. When people used cycling and walking equally frequent (and did not use the car), they were categorized as cyclist.

\subsection{Perceived accessibility}

Participants were asked (5-point Likert scale: 'strongly agree', 'agree', 'neutral', 'disagree', and 'strongly disagree') if they perceived shops, public natural spaces and sports facilities to be accessible in their neighbourhood (a) by car, (b) by bicycle and (c) by foot. The answers were dichotomized and presented as the proportion that answered 'strongly agree' or 'agree'. We were unable to investigate the influence of perceived accessibility of work facilities, since questions about this topic were not incorporated in the questionnaire.

\subsection{Personal characteristics}

Gender (male/female (reference)), age (years), educational level (low, medium, high (reference)), household composition (living alone, with a partner, with children younger than 18 years, with other adults (parents, children 18 years and older, or other adults; reference)) and physical activity level were taken into account as covariates. Regarding educational level, 'low' was defined as primary school and lower general secondary education; 'medium' as intermediate vocational education, higher general secondary education, and preuniversity education; and 'high' as higher vocational education and university (reference). Physical activity was assessed with the validated 'Short QUestionnaire to ASsess Health-enhancing physical activity' (SQUASH), which contains questions about multiple activities referring to a normal week in the past months (de Hollander et al., 2012; Wendel-Vos et al., 2003). Results from the SQUASH were converted to time (hours per week) spent on total physical activity including commuting, household, leisure time and sport activities (de Hollander et al., 2012; Wendel-Vos et al., 2003; Kemper et al., 2000). 
According to the literature, season is a potential confounder in the association between trip purpose and transport choice (McCormack et al., 2010). Therefore, we decided to correct for season (winter, spring, summer, autumn (reference)) in this study. Season was determined by the date respondents filled in the questionnaire.

\subsection{Perceived characteristics of the direct living environment}

Several perceived features of the respondents' direct living environment were taken into account as covariates: satisfaction with living environment, housing maintenance, perceived availability of parking facilities, traffic safety and availability of routes when walking or cycling (Table 1). Except for satisfaction with the living environment, answers were dichotomized and presented as the proportion that answered 'strongly agree' or 'agree'.

\subsection{Objective characteristics of the direct living environment obtained by GIS}

Since aim of this study was to provide insight into the association between perceived accessibility and choice of transport mode, while taking into account objective accessibility, data about several objective characteristics of the direct living environment were obtained. For obtaining this information, we used both four-digit and six-digit postal codes of the areas of the participants' addresses. In the Netherlands there are 4061 four-digit postal codes, representing on average 1772 households each. In urban areas this four-digit postal code represents only one neighbourhood, whereas in rural areas this postal code can represent a whole village. These four-digit postal codes can be further divided into six-digit postal codes by adding two letters resulting in a total 452490 six-digit postal codes, representing on average $15-20$ households each. The objective characteristics, except for neighbourhood typology, were obtained by using ArcGis 10.1 .

To adjust for neighbourhood typology, we merged our dataset with a dataset from ABF Research (2009) by using the four-digit postal codes of the areas of the participants' address (ABF Research, 2013). Neigbourhood typology presents a combination of various environmental characteristics. The data source (ABF Research) provided five different typologies based on density, accessibility/connectivity, land use mix and quality of buildings:

(1) Urban-centre: city centres as well as some neighbourhoods just outside the centre (reference).

(2) Urban-outside centre: neighbourhoods with a larger distance from the city centre but with a higher density than the neighbourhoods classified as 'urban-green'. Most of the time the density of these neighbourhoods is also higher than in the urban-centre neighbourhoods.

(3) Urban-green: neighbourhoods which are predominantly residential areas. Density is lower than the mean density based on housing supply. New housing estate neighbourhoods are also classified as urban-green.

(4) Village-centre: Neighbourhoods with a higher density or more facilities than rural neighbourhoods.

(5) Rural: Neighbourhoods with a low density or relatively few facilities.

In the Netherlands, neighbourhood lay-out was found to differ between different building periods (Wagenaar, 2011). Since there is a close link between neighbourhood lay-out and accessibility, we also adjusted for this building period of the residents' neighbourhood in our study. For this purpose, we gathered information about the building years of all buildings from the 2013 release of the Dutch registration of addresses and buildings (in Dutch: 'Basisregistratie Adressen en Gebouwen (BAG)') (Kadaster, 2014). Buildings were first categorized into the following historical periods of urban planning: before 1910, 1910 to 1940,1940 to 1970,1970 to 1985 and 1985 and younger. Then we assigned a specific historical period to each six-digit postal code by determining in which period most buildings were built. If the number of buildings built in two historical periods was equal, we assigned the oldest historical period to this area.

Table 1

Questions in questionnaire about people's perceptions to their direct living environment.

\begin{tabular}{|c|c|}
\hline Question & Possible answers \\
\hline \multicolumn{2}{|l|}{ Satisfaction } \\
\hline $\begin{array}{l}\text { How satisfied are you with your living environment? } \\
\text { Housing maintenance }\end{array}$ & Range $1-10^{\mathrm{a}}$ \\
\hline The distance between houses in my living environment is large enough & 5-point Likert scale ${ }^{\mathrm{b}}$ \\
\hline The buildings in my living environment are attractive & 5-point Likert scale \\
\hline $\begin{array}{l}\text { The buildings in my living environment are well maintained } \\
\text { Traffic safety }\end{array}$ & 5-point Likert scale \\
\hline In my living environment there are a lot of traffic calming measures & 5-point Likert scale \\
\hline The amount of traffic in my living environment makes it hard or unpleasant to walk & 5-point Likert scale \\
\hline $\begin{array}{l}\text { In my living environment many persons violate the speed limits } \\
\text { Availability of routes }\end{array}$ & 5-point Likert scale ${ }^{b}$ \\
\hline In my living environment, safe routes for pedestrians and cyclists are available & 5-point Likert scale ${ }^{\mathrm{b}}$ \\
\hline In my living environment, crossing places are conveniently arranged & 5-point Likert scale \\
\hline There are enough sidewalks in my living environment & 5-point Likert scale ${ }^{\mathrm{b}}$ \\
\hline There are enough cycle tracks in my living environment & 5-point Likert scale ${ }^{b}$ \\
\hline $\begin{array}{l}\text { Availability of parking facilities } \\
\text { There is a high level of parking inconvenience in my living environment }\end{array}$ & 5-point Likert scale ${ }^{\mathrm{b}}$ \\
\hline
\end{tabular}


Table 2

Characteristics of the study population.

\begin{tabular}{|c|c|c|}
\hline & $\operatorname{Men}(N=1648)$ & $\begin{array}{l}\text { Women } \\
(N=1588)\end{array}$ \\
\hline Age (Mean (SD)) & $49.8(14.6)$ & $48.0(14.2)$ \\
\hline \multicolumn{3}{|l|}{ Educational level (\%) } \\
\hline Low & 24.70 & 33.25 \\
\hline Medium & 44.48 & 41.44 \\
\hline High & 30.82 & 25.31 \\
\hline \multicolumn{3}{|l|}{ Household composition (\%) } \\
\hline Alone & 19.78 & 20.72 \\
\hline Partner & 41.57 & 38.66 \\
\hline Children $<18$ years & 21.11 & 24.87 \\
\hline $\begin{array}{l}\text { Other adults (children } \geq 18 \text { years, } \\
\text { parents, or other adults) }\end{array}$ & 17.54 & 15.74 \\
\hline Physical activity (h/wk; mean(SD)) & $19.3(16.4)$ & $22.7(16.9)$ \\
\hline \multicolumn{3}{|l|}{ Season (\%) } \\
\hline Winter & 25.91 & 26.95 \\
\hline Spring & 21.42 & 21.47 \\
\hline Summer & 25.61 & 25.69 \\
\hline Autumn & 27.06 & 25.88 \\
\hline Trip purpose: shopping (\%) & 92.60 & 92.13 \\
\hline Trip purpose: sports $(\%)$ & 46.36 & 45.27 \\
\hline Trip purpose: public natural spaces (\%) & 72.94 & 73.05 \\
\hline
\end{tabular}

Notes: Educational level: low (primary school and lower general secondary education), medium (intermediate vocational education, higher general secondary education and pre-university education) and high (higher vocational education and university). Neighbourhood typology: rural (low density or few facilities), village-centre (higher density or more facilities than rural neighbourhoods), urban-green (predominantly residential areas, with density lower than the mean density based on housing supply, or new housing estate neighbourhoods), urban-outside centre (larger distance from the city centre, but with higher density than the 'urban-green' neighbourhoords, density of these neighbourhoods is most of the time also higher than in the urban-centre neighbourhoods), and urban-centre (city centres as well as some neighbourhoods just outside the centre).

Since it was expected that road traffic noise and air pollution levels are important characteristics of the living environment in relation to transport choice (Winters et al., 2011), data were gathered for all six-digit postal codes of the respondents' home locations, which enabled us to correct for noise and air pollution. For the estimation of noise and air pollution levels we used the midpoint of the six-digit postal code area where the respondent's home was located and linked this with the Dutch National EMPARA model (Blom et al., 2008). The Noisetool of EMPARA has been used to obtain levels of road traffic noise exposure (expressed in $L_{\mathrm{den}}$, i.e. the day-evening noise level: the yearly averaged equivalent sound level over $24 \mathrm{~h}$ ) from nationally available noise maps. Modelled noise data from 2008 and 2009 , with a resolution of $25 \times 25 \mathrm{~m}^{2}$ grids were linked to the midpoint of the six-digit postal code area. To assess air pollution exposure we used the Luvotool of EMPARA to model concentrations $\left(\mu \mathrm{g} / \mathrm{m}^{3}\right)$ for nitrogen dioxide $\left(\mathrm{NO}_{2}\right)$ at this midpoint of the six-digit postal code area. These concentrations were estimated with a resolution of $100 \times 100 \mathrm{~m}^{2}$ grids. Modelled air pollution data were constructed on the basis of 2009 annual mean concentrations from the Dutch national air quality network, supplemented with data on traffic, population, topography and land use.

Accessibility of the three types of facilities (shopping, public natural spaces and sports) was additionally operationalized by assessing straight line distances from the midpoint of the six-digit postal code area where the respondent lives to the closest facilities. The location and function of the shopping facilities were obtained from the BAG (Kadaster, 2014) and the Standard Company Classification by Statistics Netherlands in 2012 (Statistics Netherlands, 2013). Location and function of the sports facilities were obtained from the Accommodation Monitor Sports of the Mulier Institute (Mulier Institute). The location and the surface of the public natural spaces (forest, park, sea and small blue areas) were obtained from TOP10NL (Public services on the map (PDODK), 2008). The function of these public natural spaces was obtained from a land use map of Statistics Netherlands (Statistics Netherlands, 2008). The distance to these facilities was calculated by using a straight line from the midpoint of the six-digit postal code where the respondents' home was located to the nearest grocery store (as a proxy for shopping), public natural spaces and sports facilities. We also determined the availability of these facilities within a distance of $7.5 \mathrm{~km}$ of the midpoint of the six-digit postal code by counting the number of these facilities or, in case of the public natural spaces, determining the surface area $\left(\mathrm{km}^{2}\right)$ of public natural spaces. For a part of the participants (11\%), a proportion of the surface within the $7.5 \mathrm{~km}$ radius was located outside the borders of the Netherlands. To correct for this, the number of facilities and area of public natural spaces were divided by the surface that was located within the Netherlands. In the remainder of this article, we will refer to this proportion of facilities within a circle with a radius of $7.5 \mathrm{~km}$ as the availability of facilities.

Availability of separate walking and cycle tracks was determined by counting the total length of these tracks within a circle with a radius of $7.5 \mathrm{~km}$ by using OpenStreetMap, which gives detailed information on separate walking and cycling tracks. This length was also corrected for the proportion of surface that was located within the Netherlands.

\subsection{Data analyses}

Participants with missing values on one or more confounding variables $(N=72)$ or extreme values on time spent (hours per week) on total physical activity $(N=33)$ were excluded from statistical analyses. Ultimately, statistical analyses included data concerning 3236 respondents. Descriptive statistics were carried out to characterize the study population. Pearson's chi-square tests were used to test for 
Table 3

Objective environmental characteristics and perception of the living environment.

Total $(N=3236)$

\begin{tabular}{|c|c|}
\hline \multicolumn{2}{|l|}{ Neighbourhood typology (\%) } \\
\hline Rural & 8.44 \\
\hline Village centre & 31.37 \\
\hline Urban-green & 13.38 \\
\hline Urban-outside centre & 38.81 \\
\hline Urban-centre & 8.00 \\
\hline \multicolumn{2}{|l|}{ Historical building period of residents' neighbourhood (\%) } \\
\hline Before 1910 & 9.36 \\
\hline $1910-1940$ & 30.07 \\
\hline $1940-1970$ & 33.96 \\
\hline 1970-1985 & 24.35 \\
\hline 1985 and younger & 2.26 \\
\hline Length of cycle tracks per $\mathbf{k m}^{2}(\mathrm{~km}$; mean(SD)) & $1.5(0.9)$ \\
\hline Length of walking tracks per $\mathbf{k m}^{2}(\mathbf{k m}$; mean(SD)) & $1.2(1.0)$ \\
\hline Shortest distance to grocery store (km; mean(SD)) & $0.8(0.9)$ \\
\hline Number of grocery stores within a radius of $7.5 \mathrm{~km}$ (mean (SD)) & $17.6(13.9)$ \\
\hline Shortest distance to public natural space & $0.2(0.2)$ \\
\hline Percentage of public natural spaces within a radius of $7.5 \mathbf{~ k m}$ (mean (SD)) & $18.5(10.9)$ \\
\hline Shortest distance to sports facility & $0.5(0.4)$ \\
\hline Number of sport facilities within a radius of $7.5 \mathrm{~km}$ (mean (SD)) & $57.8(35.2)$ \\
\hline Yearly-averaged $\mathrm{NO}_{2}$-concentration $\left(\mu \mathrm{g} / \mathrm{m}^{3}\right)(\mathrm{SD})$ & $24.1(5.9)$ \\
\hline Road traffic noise exposure (Lden) (SD) & $53.8(4.6)$ \\
\hline \multicolumn{2}{|l|}{ Perception of the living environment } \\
\hline Satisfaction with living environment (score with range 1 (very unsatisfied) till 10 (very satisfied); mean (SD)) & $7.7(1.2)$ \\
\hline \multicolumn{2}{|l|}{ Housing maintenance } \\
\hline The distance between houses is large enough (\%) & 65.51 \\
\hline Buildings are attractive (\%) & 65.08 \\
\hline Buildings are well maintained (\%) & 76.64 \\
\hline \multicolumn{2}{|l|}{ Traffic safety } \\
\hline There are a lot of traffic calming measures (\%) & 67.40 \\
\hline Amount of traffic makes it hard or unpleasant to walk (\%) & 8.07 \\
\hline Many persons violate speed limits (\%) & 40.61 \\
\hline \multicolumn{2}{|l|}{ Availability of routes } \\
\hline Availability of safe routes for pedestrians and cyclists (\%) & 72.40 \\
\hline Crossing places are conveniently arranged (\%) & 62.30 \\
\hline There are enough sidewalks (\%) & 80.50 \\
\hline There are enough cycle tracks (\%) & 77.44 \\
\hline \multicolumn{2}{|l|}{ Availability of parking facilities } \\
\hline There is a high level of parking inconvenience (\%) & 28.71 \\
\hline
\end{tabular}

potential differences in perceived accessibility of shopping facilities, sports facilities and public natural spaces between car users, cyclists and pedestrians $(p<0.05)$.

To investigate the association between perceived accessibility of facilities and choice of transport, logistic regression analysis were used to model the odds of cycling versus car use and to model the odds of walking versus car use. In this paper, we examined the following three models per trip purpose:

Model 1: transport Perceived accessibility;

choice $=$

Model 2: transport Perceived accessibility+gender + age + education level + household composition + neighbourhood typolo-

choice $=$ gy + historical building period of residents' neighbourhood + season + physical activity level + availability of cycling/walking tracks + noise + air pollution + satisfaction with living environment + housing maintenance + parking facilities + traffic safety + availability of routes;

Model 3: transport Perceived accessibility + gender + age + education level + household composition + neighbourhood typolochoice $=$ gy + historical building period of residents' neighbourhood + season + physical activity level + availability of cycling/walking tracks + noise + air pollution + satisfaction with living environment + housing maintenance + parking facilities + traffic safety + availability of routes + objective indicators for accessibility.

The presented OR's may be interpreted as the likelihood of an average person in our dataset choosing active transport over using the car for trips up to $7.5 \mathrm{~km}$. For these statistical analyses, SAS 9.3 was used.

\section{Results}

Tables 2 and 3 show the characteristics of the study population included in the analyses. It shows a nearly comparable distribution for men and women for almost all variables. A low education level was more prevalent among women (33.3\%) than among men (24.7\%). Table 4 shows that the perceived accessibility of facilities differed significantly between car users, cyclists and pedestrians for nearly all 
Table 4

Perceived accessibility per trip purpose and transport mode.

\begin{tabular}{|c|c|c|c|c|c|c|c|c|c|c|c|c|}
\hline & \multicolumn{4}{|c|}{ Shopping } & \multicolumn{4}{|c|}{ Public natural spaces } & \multicolumn{4}{|l|}{ Sports } \\
\hline & $\begin{array}{l}\text { Car } \\
\text { users }\end{array}$ & Cyclists & Pedestrians & $p$ & $\begin{array}{l}\text { Car } \\
\text { users }\end{array}$ & Cyclists & Pedestrians & $p$ & $\begin{array}{l}\text { Car } \\
\text { users }\end{array}$ & Cyclists & Pedestrians & $p$ \\
\hline $\begin{array}{l}\text { The facility is well accessible by walk- } \\
\text { ing (\%) }\end{array}$ & 67.96 & 83.10 & 96.27 & $<0.01^{*}$ & 52.87 & 65.20 & 74.65 & $<0.01^{*}$ & 43.16 & 61.87 & 84.78 & $<0.01^{*}$ \\
\hline $\begin{array}{l}\text { The facility is well accessible by cycling } \\
(\%)\end{array}$ & 91.39 & 98.08 & 96.71 & $<0.01^{*}$ & 78.34 & 86.86 & 84.31 & $<0.01^{*}$ & 85.09 & 96.71 & 95.11 & $<0.01^{*}$ \\
\hline The facility is well accessible by car (\%) & 96.50 & 85.43 & 78.73 & $<0.01^{*}$ & 77.39 & 76.08 & 74.09 & 0.36 & 97.89 & 91.08 & 85.33 & $<0.01^{*}$ \\
\hline
\end{tabular}

Notes:

* Pearson's chi-square test: $p<0.05$

Table 5

Association between perceived accessibility and transport choice (OR (95\%)).

\begin{tabular}{|c|c|c|c|c|c|c|c|}
\hline & & \multicolumn{3}{|l|}{ Cycling vs. car use } & \multicolumn{3}{|l|}{ Walking vs. car use } \\
\hline & & Shopping & $\begin{array}{l}\text { Public natural } \\
\text { spaces }\end{array}$ & Sports & Shopping & $\begin{array}{l}\text { Public natural } \\
\text { spaces }\end{array}$ & Sports \\
\hline \multirow[t]{3}{*}{$\begin{array}{l}\text { The facility is well accessible by } \\
\text { walking }\end{array}$} & Model 1 & & & & $14.37(8.56-24.11)$ & $2.92(2.30-3.72)$ & $\begin{array}{l}8.70(5.42- \\
13.97)\end{array}$ \\
\hline & Model 2 & & & & $12.89(7.42-22.38)$ & $3.06(2.37-3.95)$ & $\begin{array}{l}9.77(5.81- \\
16.41)\end{array}$ \\
\hline & Model 3 & & & & $11.22(6.39-19.70)$ & $2.97(2.30-3.85)$ & $\begin{array}{l}8.82(5.22- \\
14.90)\end{array}$ \\
\hline \multirow[t]{3}{*}{$\begin{array}{l}\text { The facility is well accessible by } \\
\text { cycling }\end{array}$} & Model 1 & $8.14(4.75-13.95)$ & $2.49(1.81-3.43)$ & $\begin{array}{l}9.77(5.41- \\
16.65)\end{array}$ & & & \\
\hline & Model 2 & $6.77(3.85-11.92)$ & $2.22(1.59-3.11)$ & $\begin{array}{l}10.76(5.86- \\
19.77)\end{array}$ & & & \\
\hline & Model 3 & $6.21(3.51-10.99)$ & $2.18(1.55-3.07)$ & $\begin{array}{l}10.43(5.65- \\
19.26)\end{array}$ & & & \\
\hline \multirow[t]{3}{*}{ The facility is well accessible by car } & Model 1 & $0.15(0.10-0.21)$ & $0.60(0.45-0.80)$ & $0.09(0.04-0.19)$ & $0.10(0.07-0.16)$ & $0.62(0.47-0.81)$ & $0.08(0.04-0.18)$ \\
\hline & Model 2 & $0.17(0.12-0.26)$ & $0.66(0.48-0.89)$ & $0.09(0.04-0.21)$ & $0.15(0.10-0.24)$ & $0.62(0.47-0.83)$ & $0.09(0.03-0.22)$ \\
\hline & Model 3 & $0.18(0.12-0.26)$ & $0.66(0.49-0.90)$ & $0.10(0.04-0.22)$ & $0.14(0.09-0.23)$ & $0.62(0.47-0.83)$ & $0.09(0.03-0.22)$ \\
\hline
\end{tabular}

Abbrevations; OR=Odds Ratio indicating the odds to use active transport modes for a short trip; $95 \% \mathrm{CI}=95 \%$ confidence interval; significance was tested at $\alpha=0.05$.

trip purposes. Car users perceived the different facilities to be less accessible by cycling or walking whereas pedestrians and cyclist perceived the facilities to be most accessible by their preferred transport mode.

\subsection{Accessibility and transport choice}

Table 5 shows the odds ratios (OR) and their 95\% confidence intervals (CI) for the association between perceived accessibility and transport choice per trip purpose. Since no large differences were found between the three models, only the odds ratios of the full model (model 3) will be discussed in this paper. Irrespective of the different covariates, perceived accessibility of the different facilities was found to be associated with active transport use for all trip purposes. When perceived accessibility of the facilities by car was high, persons were more likely to use the car (OR range: 0.09-0.66). When perceived accessibility by active transport modes was high, persons were more likely to use the bicycle (OR range: 2.18-10.43) or walk (OR range: 2.97-11.22). In general, associations for shopping and sport trip purposes were found to be stronger than associations for trips to public natural spaces (cycling vs. car use and walking vs. car use).

\section{Discussion}

Perceived accessibility was found to be strongly associated with transport choice for trips made with the purpose of shopping, going to sports facilities or going to public natural spaces, irrespective of objective accessibility. When perceived accessibility by car was high, persons were more likely to use the car instead of active transport modes. Likewise, when perceived accessibility by bicycle or walking was high, persons were more likely to make the trips with these active transport modes.

\subsection{Perceived accessibility}

Perceived accessibility of facilities was found to be associated with transport choice. In line with this, Van Holle et al. (2012) showed in a systematic review of European studies that there is convincing evidence for a positive relationship between active transportation (combination of walking and cycling or cycling only) and access to shops/services/work. However, they found no evidence for a relation between active transportation and access to recreation facilities (including greenery and places or facilities for physical activity). In our 
study, we also found evidence for an association between perceived accessibility of sports facilities and public natural spaces and transport choice. This difference could be explained by the unique cycling environment of The Netherlands and the large amount of short trips by the Dutch (Ministry of Transport Public Works and Water Management, 2009; Pucher and Buehler, 2008).

\subsection{Strengths and limitations}

In this study we used a questionnaire specifically designed to investigate transport choice and perceived accessibility for three predefined trip purposes. This enabled us to study transport choice in more detail. We included both perceived and objective measures of accessibility in our model, since it was expected that physical activity behaviour not only depends on the perceived environment but also on the objective environment (McCormack et al., 2008). As already mentioned, previous studies (McCormack et al., 2008; Ball et al., 2008) have shown there is poor agreement between these perceived and objective measures. This was also the case in our study. Including both perceived and objective measures in our model enabled us to draw stronger conclusions about the influence of perceived accessibility measures.

To be able to correct for objective environmental measures we merged our dataset with several objective datasets. Though, in the present study, we used only a rough classification of neighbourhood typology and building period of residents' neighbourhood as well as we used shortest distances instead of actual distances. Therefore, more detailed information concerning environmental characteristics for developing neighbourhoods supporting active transport is needed. For these purposes, case studies will be more suitable, since they may more easily yield detailed information on environmental characteristics than large scale national studies such as the present one.

Correcting for these objective measures did not change the association between perceived accessibility and transport choice much and enabled us to define a stronger conclusion concerning perceived accessibility. However, we had no information about the exact destinations of our respondents. Therefore, we were unable to calculate the exact distances. Future studies should also gather information about actual destinations as well as the route taken to reach them (for example by using GPS tracking) to be able to measure distances accurately.

One way to nudge healthy behaviour is by designing neighbourhoods that facilitate such behaviour (e.g. active transport) (Timmermans, 2013). In this study we only focused on perceived accessibility in relation to transport choice. Since transport choice is expected to be habitual for some trip purposes, these habits could have influenced respondents' answers with regard to perceived accessibility. It has been argued that persons performing habitual behaviour are more likely to change their attitudes to correspond with their habitual behaviour rather than to change the behaviour itself (self-fulfilling prophecy) (Berveling et al., 2011).

St-Louis et al. (2014) found that trip satisfaction was influenced by different determinants for different travel modes and also argue that family habits can influence an individual's commute experience. Therefore, as a sensitivity analysis we only included those persons who indicated to use a specific transport mode because they are used to take that mode. However, this did not influence any of our main findings (data not shown). The desire to walk has also been argued to influence the relationship between perceived accessibility and transport choice. To explore this influence we did a sensitivity analysis including only persons who indicated to use a specific transport mode because they liked to use that transport mode. The results of this sensitivity analysis did also not influence our main findings (data not shown). Qualitative research (for example focus groups) is needed to be able to elucidate this influence of habits and desire on the perception of the neighbourhood and motivations of transport choice.

\subsection{Implications of our study}

Irrespective of objective accessibility, our study shows that perceived accessibility is strongly associated with transport choice. It can be argued that perceived accessibility is of great importance when stimulating transport choice. Our study implies that future interventions should focus on perceived accessibility when stimulating active transport use.

\section{Conclusions}

The aim of the present study was to provide insight into the association between perceived accessibility and choice of transport mode for shopping trips, trips to sports facilities and trips to public natural spaces. Perceived accessibility was found to be strongly associated with transport choice for all trip purposes. Our results suggest that perceived accessibility should be taken into account when stimulating a shift from car use to cycling or walking. However, more detailed information about these trip purposes and living environments is needed to allow development of suitable interventions or policy measures.

\section{Acknowledgements}

The authors thank W. Swart from the National Institute for Public Health and the Environment for deriving data on noise and air pollution levels and K. Wezenberg-Hoenderkamp from the Mulier Institute for deriving data on sport facilities.

The AVENUE project is commissioned and financed by the Dutch National Institute for Public Health and the Environment (RIVM, grant number S/260256/01/AV) as part of the strategic research program. 


\section{Appendix A. Representativeness of our study population on mobility behaviour and personal characteristics}

\section{Mobility behaviour}

Representativeness of our study population was checked by comparing results on mobility behaviour for shopping and commuting trips with data from Research Transportation Netherlands (OViN) from Statistics Netherlands (Statistics Netherlands, 2012). Since trips to public natural spaces were not specified in OViN and trips to sport facilities were merged with trips to hobby facilities, we were unable to compare transport behaviour for these two trip purposes. In line with results obtained by OViN, most short trips were made for shopping purposes. However, in our study population less shopping trips were made by car (36.7\% vs. $41.5 \%)$ and more shopping trips by walking (27.3\% vs. $22.7 \%$ ). Also slightly more commuting trips were made by walking (12.2\% vs. 9.2\%) in our study.

\section{Personal characteristics}

Personal characteristics (e.g. gender, age, education level, satisfaction with living environment) were checked with data from Statistics Netherlands. Comparing the proportion of men and women in our study population with the Dutch population showed that our study population consisted of more men (51.2\% vs. 49.5\%). The mean age of the total Dutch population was 40.8 years old in 2013 . However, $23.1 \%$ of the Dutch population was younger than 20 years old. Since we included only persons of 18 years and older in our study population this could explain the age difference with our study population (men: 49.9 years old; women: 48.5 years old). A low education level was more prevalent in our study population (men: $26.2 \%$, women: $36.1 \%$ ) than in the Dutch population (22.6\%). Comparison of mean satisfaction with the living environment showed no differences between our study population and the Dutch population (7.7 vs. 7.5 ).

\section{Appendix B. Non-response research}

3308 of the non-responding participants received another link to a short non-response questionnaire. A total of 445 (13.5\%) respondents started with the non-response questionnaire. Differences between non-respondents and respondents were tested by using an independent $t$-test for continual variables and a Pearson chi-square test for categorical variables. $P$-levels lower than 0.05 were considered significant.

In line with the actual questionnaire, participants were asked the two selection questions:

1) To what extent does your health hamper you in (a) walking; (b) cycling; (c) driving a car?

Possible answers: very much, somewhat, practically not, not at all.

2) How many times a week do you normally travel distances up to $7.5 \mathrm{~km}$ by (a) car; (b) bicycle; (c) foot?

Possible answers: never, < once a week, $\geq$ once a week, do not know.

A total of 398 non-respondents (89.4\%) indicated that they were not hampered ('practically not' or 'not at all') to use at least one of the three transport modes and that they made at least one short trip a week using at least one of the transport modes. A total of 4021 respondents (90.5\%) indicated this was the case. Comparing the answers of the non-respondents on these selection questions with our participants showed no significant differences between the non-respondents and respondents (Table S2.1).

Besides these selection questions, non-respondents were also asked about personal characteristics (date of birth, gender, household composition), trip purposes and accompanying transport mode, satisfaction with the living environment and household composition. Information about education level was obtained from the panel background dataset. Significant differences between the non-respondents and respondents were found for age, household structure and making trips to public natural spaces (Table S2.2). Living with children with an age lower than 18 years old was more prevalent among non-respondents (31.9\%) than among respondents (21.9\%). This could also explain the slightly lower mean age (47.3 vs. 49.4 years old) among the non-respondents. Transport choice for trips to public natural spaces was also found to be significantly different between non-respondents and respondents, which could also be explained by the lower age and the differences in household composition.

\section{Appendix C. Supplementary material}

Supplementary data associated with this article can be found in the online version at http://dx.doi.org/10.1016/j.jth.2016.01.003.

\section{References}

ABF Research. ABF Neighbourhood typologies. Delft. 〈http://www.abfresearch.nl/media/644840/woonmilieutypologie.pdf (accessed October 2013) (in Dutch).

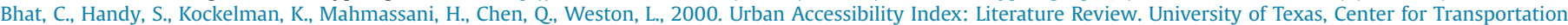
Research, Austin, TX.

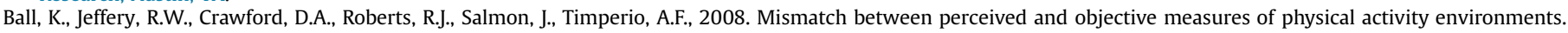
Prev. Med. 47 (3), 294-298. http://dx.doi.org/10.1016/j.ypmed.2008.05.001.

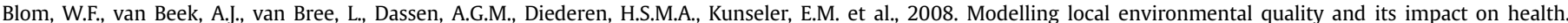
Background Document for an International Scientific Audit of PBL team LOK. Bilthoven: Netherlands Environmental Assessment Agency (PBL), August 2008. Report No.: 550034001.

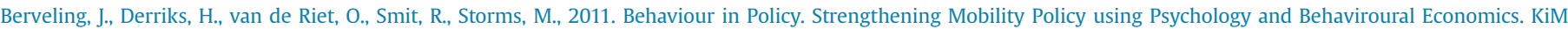
Netherlands Institute for Transport Policy Analysis, Ministry of Infrastructure and the Environment, Den Haag (in Dutch).

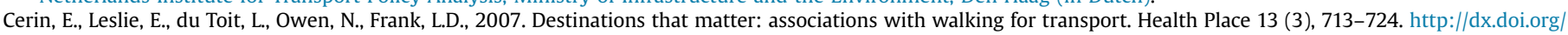
10.1016/j.healthplace.2006.11.002.

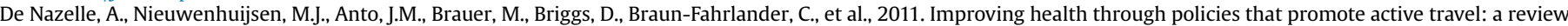
of evidence to support integrated health impact assessment. Environ. Int. 37 (4), 766-777. http://dx.doi.org/10.1016/j.envint.2011.02.003. 


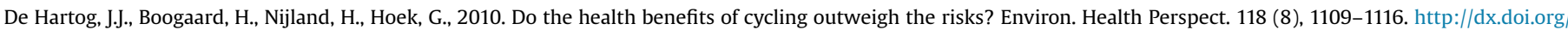
10.1289/ehp.0901747.

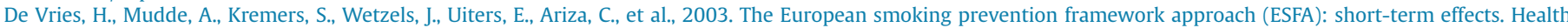
Educ. Res. 18 (6), 649-663, discussion 64-77.

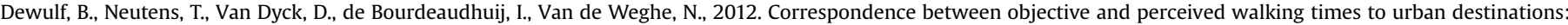
influence of physical activity, neighbourhood walkability, and socio-demographics. Int. J. Health Geogr. 11, 43. http://dx.doi.org/10.1186/1476-072X-11-43.

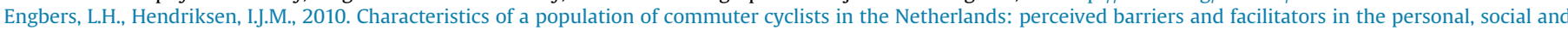
physical environment. Int. J. Behav. Nutr. Phys. Act. 7 (89).

Kemper, H., Ooijendijk, W., Stiggelbout, M., 2000. Consensus about the Dutch physical activity guideline. TSG 78, $180-183$.

Kadaster. Basisregistratie Adressen en Gebouwen (BAG). 〈http://www.kadaster.nl/bag (accessed 24 January 2014).

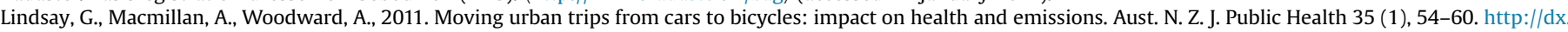
doi.org/10.1111/j.1753-6405.2010.00621.x.

Metz, D., 2013. Mobility, access, and choice: a new source of evidence. J. Transp. Land Use 6 (2), 1-4.

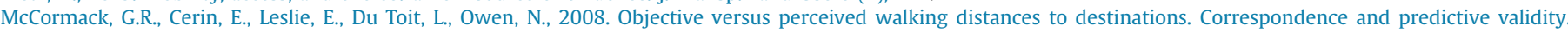
Environ. Behav. 40 (3), 401-425.

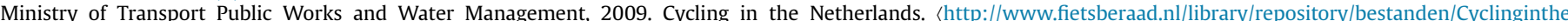
Netherlands2009.pdf) (accessed October 2013).

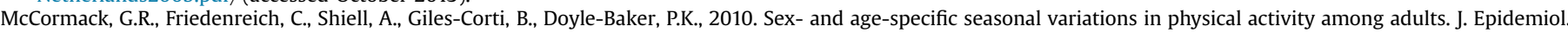
Community Health 64 (11), 1010-1016. http://dx.doi.org/10.1136/jech.2009.092841.

Mulier Institute. Accommodation Monitor Sports 〈www.mulierinsituut.nl〉.

Pucher, J., Buehler, R., 2008. Making cycling irresistible: lessons form the Netherlands, Denmark and Germany. Transp. Rev. 28 (4), $495-528$.

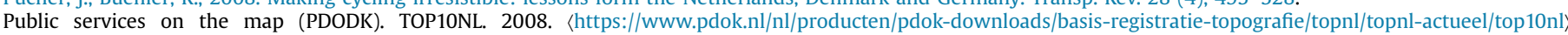
(accessed 1 November 2013).

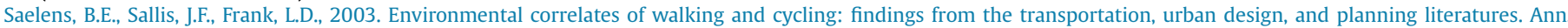
Behav. Med. 25 (2), 80-91.

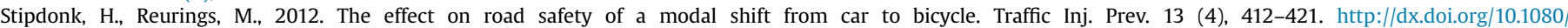
15389588.2012 .660661

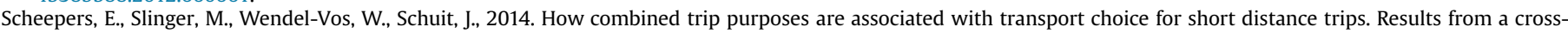
sectional study in the Netherlands. PLoS ONE 9 (12), e114797. http://dx.doi.org/10.1371/journal.pone.0114797.

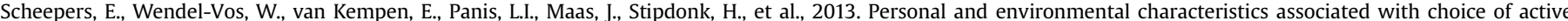
transport modes versus car use for different trip purposes of trips up to $7.5 \mathrm{~km}$ in The Netherlands. PLoS One 8 (9), e73105. http://dx.doi.org/10.1371/journal. pone.0073105, doi:10.1371/journal.pone.0073105.

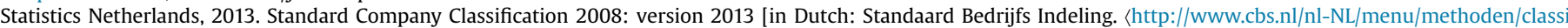
ficaties/overzicht/sbi/sbi-2008/default.htm $\rangle$ (accessed 23 December 2013).

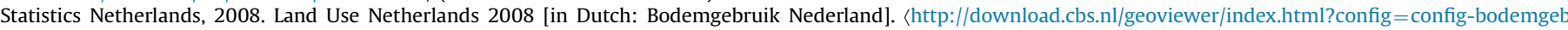
ruik-2008.xml> (accessed 1 November 2013).

St-Louis, E., Manaugh, K., van Lierop, D. El-Geneigy, A., 2014. The happy commuter: a comparison of cummuter satisfaction across modes. Transp. Res. F 26, 160-170. Statistics Netherlands, 2013. Research Transportation Netherlands 2012. The research. Den Haag/Heerlen (in Dutch).

Timmermans, D., 2013. What drives the persons making choices? About the meanings of conscious and informed choices for health and prevention. ZonMw2013.

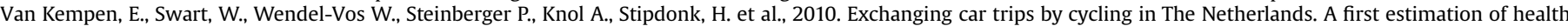
benefits. RIVM Report 630053001/2010. RIVM, Bilthoven.

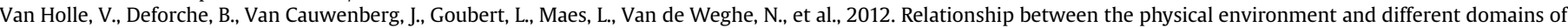
physical activity in European adults: a systematic review. BMC Public Health 12, 807. http://dx.doi.org/10.1186/1471-2458-12-807.

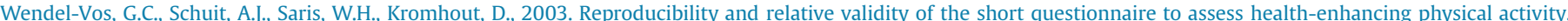
J. Clin. Epidemiol. 56 (12), 1163-1169.

Wagenaar, C., 2011. Town Planning in The Netherlands Since 1800. 010 Publisher, Rotterdam.

Winters, M., Davidson, G., Kao, D., Teschke, K., 2011. Motivators and deterrents of bicycling: comparing influences on decisions to ride. Transportation 38 , $153-168$.

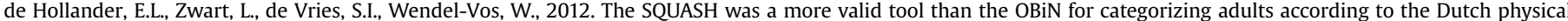
activity and the combined guideline. J. Clin. Epidemiol. 65 (1), 73-81. http://dx.doi.org/10.1016/j.jclinepi.2011.05.005.

co OpenStreetMap contributors. OpenStreetMap. 〈http://www.openstreetmap.org (accessed 1 October 2013). 